\title{
Proteomic profiling of human HepG2 cells treated with hesperidin using antibody array
}

\author{
SILVIA YUMNAM ${ }^{1}$, VENU VENKATARAME GOWDA SARALAMMA ${ }^{1}$, SUCHISMITA RAHA $^{1}$, \\ HO JEONG LEE ${ }^{1}$, WON SUP LEE ${ }^{2}$, EUN HEE KIM ${ }^{3}$, SANG JOON LEE ${ }^{4}$, JEONG DOO HEO $^{4}$ and GON SUP KIM ${ }^{1}$ \\ ${ }^{1}$ Research Institute of Life Science, College of Veterinary Medicine, Gyeongsang National University, \\ Jinju, Gyeongsang 52828; ${ }^{2}$ Department of Internal Medicine, Institute of Health Sciences, Gyeongsang National University \\ School of Medicine, Jinju, Gyeongsang 52727; ${ }^{3}$ Department of Nursing Science, International University of \\ Korea, Jinju, Gyeongsang 52833; ${ }^{4}$ Gyeongnam Department of Environment Toxicology and Chemistry, \\ Gyeongnam Biological Resource Research Center, Korea Institute of Toxicology, Jinju, Gyeongsang 52834, Republic of Korea
}

Received April 3,2017; Accepted June 11, 2017

DOI: $10.3892 / \mathrm{mmr} .2017 .7232$

\begin{abstract}
Protein array technology not only identifies a large number of proteins but also determines their expression levels. In the present study, antibody array analysis is used to decipher the proteins involved in hesperidin-induced cell death in HepG2 cells. Altered proteins in hesperidin treated cells were compared with that of untreated control cells by using a RayBio ${ }^{\circledR}$ Label-based (L series) human antibody array kit. The identified proteins were further confirmed using western blot analysis. STRING software based analysis was used to determine the protein-protein interactions. Many proteins related to signal transduction, cellular mechanisms, cell growth and proliferation regulatory proteins were identified. Among the proteins identified Hsp90, Smac/DIABLO, Prdx6 and FRK were significantly reduced in hesperidin treated cells. To the best of the authors' knowledge, the present study is the first to use antibody array for identifying proteins marker in hesperidin-induced cell death in HepG2 cells. The present study provides a novel insight into the anticancer mechanism of hesperidin.
\end{abstract}

Correspondence to: Professor Gon Sup Kim, Research Institute of Life Science, College of Veterinary Medicine, Gyeongsang National University, 501 Jinju-daero, Jinju, Gyeongsang 52828, Republic of Korea

E-mail: gonskim@gnu.ac.kr

Dr Jeong Doo Heo, Gyeongnam Department of Environment Toxicology and Chemistry, Gyeongnam Biological Resource Research Center, Korea Institute of Toxicology, 17 Jegok-gil, Munsan-eup, Jinju, Gyeongsang 52834, Republic of Korea E-mail: jdher@kitox.re.kr

Key words: HepG2, hesperidin, antibody array, STRING

\section{Introduction}

Hesperidin is a flavone glycoside that is abundantly present in citrus fruits. Many have reported the anticancer activity of hesperidin on malignant cancer cells such as breast and prostate cancer (1) and colon cancer (2). It also inhibits tumor invasiveness of hepatocellular carcinoma $(3,4)$. Recently, the authors reported that hesperidin induced paraptosis in human hepatoblastoma HepG2 cells (5). Paraptosis is a type of caspase independent programmed cell death that is characterized by extensive cytoplasmic vaculation with swelling of mitochondria or endoplasmic reticulum without cell membrane blebbing or nuclear fragmentation (6).

Proteomic profiling has become a promising technology and been widely used for clinical biomarker identification, pathogenesis investigation, new drug discovery, pharmacological research and toxicological examination (7). Antibody array enables parallel detection of multiple proteins with low sample volume. It is of two types: A label based assay and a sandwich assay. In a label-based assay, the targeted proteins are labeled with a tag and are then applied onto an antibody chip. The bound proteins can be visualized using a laser scanner. It is a competitive assay where the analytes in the test and reference solutions compete for binding with the antibodies leading to improvement in linearity of response and dynamic range compared with non-competitive assays, but the disadvantage of label-based assay is limited to sensitivity and specificity $(8,9)$. However, there is no study of proteomic studies of hesperidin induced cell death in human hepatoblastoma HepG2 cells. The purpose of the study is to detect protein markers in HepG2 cells treated with or without hesperidin using RayBio ${ }^{\circledR}$ Label-based (L series) human antibody array.

The antibody array analysis identified many proteins that are signal transduction proteins, structural proteins, mitochondrial proteins and proteins related to cellular metabolism. The STRING database was used to identify the protein-protein interactions of the proteins identified by antibody array. As most of the biological functions are transmitted via proteins, identification of proteins in hesperidin induced cell death will 
provide a better understanding on the anticancer mechanism of hesperidin.

\section{Materials and methods}

Chemical and reagents. Dulbecco's modified Eagle's medium (DMEM) was purchased from HyClone; GE Healthcare Life Sciences (Chalfont, UK). Antibiotics (streptomycin/penicillin) and fetal bovine serum (FBS) were obtained from Gibco; Thermo Fisher Scientific, Inc. (Waltham, MA, USA). Goat anti-rabbit IgG (no. ADI-SAB-300, 1:2,000) and horseradish peroxidase-conjugated goat anti-mouse IgG (no. ADI-SAB-100-J, 1:2,000) were both purchased from Enzo Life Sciences, Inc. (Farmingdale, NY, USA). The RayBio ${ }^{\circledR}$ Label-based (L series) human L-507 antibody array 1000 membrane kit was purchased from RayBiotech (Norcoss, GA, USA). Anti-Prdx6 (ab59543, 1:1,000) and Anti-Frk (ab64914, 1:1,000) were purchased from Abcam (Cambridge, UK). Anti-Smac (no. 15108S, 1:1,000) and Anti-Hsp90 (no. 4877S, 1:1,000) were purchased from Cell Signaling Technology, Inc. (Beverly, MA, USA).

Cell culture and treatment. HepG2 cells were obtained from Korean Cell Line Bank (Seoul, Korea) and were maintained in DMEM supplemented with $10 \%$ heat inactivated FBS and $1 \%$ penicillin/streptomycin at $37^{\circ} \mathrm{C}$ in a $5 \% \mathrm{CO}_{2}$ incubator. Cells were treated with vehicle alone (1\% DMSO) or $1 \mathrm{mM}$ hesperidin dissolved in $1 \%$ DMSO.

Antibody array. An antibody array was carried out according to the manufacturer's instructions. Overnight grown cells were treated/untreated with $1 \mathrm{mM}$ hesperidin. Following a $24 \mathrm{~h}$ incubation, cells were trypsinized and dialyzed at $4^{\circ} \mathrm{C}$. The dialyzed samples were then biotin-labeled using $1 \mathrm{X}$ labeling reagent provided in the assay kit. The membranes are then blocked in blocking buffer at room temperature with gentle shaking for $1 \mathrm{~h}$. After aspirating the blocking buffer, $8 \mathrm{ml}$ of the diluted sample is placed on each membrane and incubated at RT for $2 \mathrm{~h}$ with gentle shaking. The membranes are then washed with $1 \mathrm{X}$ washing buffer for 3 times. After washing, $1 \mathrm{X}$ horseradish peroxidase-conjugated streptavidin was added to each membrane and incubated at room temperature for $2 \mathrm{~h}$ with gentle shaking. After washing, the membranes were placed in the detection buffer for $2 \mathrm{~min}$ and then the signals were detected using a ChemiDoc imaging system (Bio-Rad Laboratories, Inc., Hercules, CA, USA). By comparing the signal intensities quantified by densitometry, relative expression levels of target proteins were made.

Protein-protein interaction. Protein-protein interactions were analyzed using Search Tool for the Retrieval of Interacting Genes (STRING database, version 10; http://string.embl.de).

Western blot analysis. Overnight grown HepG2 cells incubated with or without $1 \mathrm{mM}$ hesperidin for $24 \mathrm{~h}$ at $37^{\circ} \mathrm{C}$ were lysed overnight with radioimmunoprecipitation assay lysis buffer containing protease inhibitor cocktail and EDTA. The extracts were then centrifuged at $14,500 \mathrm{x} \mathrm{g}$ for $30 \mathrm{~min}$ at $4^{\circ} \mathrm{C}$ to remove debris. The protein concentration in the supernatants was determined using a Bradford protein assay kit
(Bio-Rad Laboratories, Inc.), according to the manufacturer's instructions. After being boiled with loading buffer, $50 \mu \mathrm{g}$ protein samples were separated by $12 \%$ SDS-PAGE and then transferred onto polyvinylidene difluoride membrane, which was blocked with 5\% non-fat milk for $1 \mathrm{~h}$. Then, membranes were incubated with primary antibodies at $4^{\circ} \mathrm{C}$ overnight. After washing five times, the membranes were incubated with respective horseradish peroxidase-conjugated secondary antibodies at $37^{\circ} \mathrm{C}$ for $3 \mathrm{~h}$. Western blot analyses were developed with enhanced chemiluminescence kit (GE Healthcare Life Sciences). Normalization was ensured by $\beta$-actin and each band was quantified using ImageJ software version 1.50i (National Institutes of Health, Bethesda, MD, USA).

Antibody array analysis. Independent replicate antibody array experiments were performed and the RayBio ${ }^{\circledR}$ Human L-507 array analysis tool software, provided with the array, was used to analyze the signal intensities of the identified proteins. The data were normalized after background subtraction with the positive control densities. The positive control of the first sample is considered as 1 and the signal intensities of other samples are calculated according to the formula: Normalized signal intensity of particular spot $=($ signal intensity of partic ular spot) $x$ (positive signal intensity on reference array/positive signal intensity on sample array).

Statistical analysis. Data are expressed as the mean \pm standard deviation of a minimum of three replicates independent experiments. A Student's t-test was performed using SPSS version 10.0 for Windows (SPSS Inc., Chicago, IL, USA). $\mathrm{P}<0.05$ was determined to indicate a statistically significant difference.

\section{Results}

Protein identification by antibody array. Antibody array analysis of HepG2 cells treated with or without hesperidin was carried out in order to identify the proteins involved in hesperidin induced cell death. As described in our previous study, paraptotic cell death was induced in HepG2 cells by treating with $1 \mathrm{mM}$ hesperidin for $24 \mathrm{~h}$ (5). Thus, for all the studies HepG2 cells treated with $1 \mathrm{mM}$ hesperidin was compared with that of untreated control cells. Total cell extract of HepG2 cells treated with or without $1 \mathrm{mM}$ hesperidin were subjected to human antibody array analysis [RayBio ${ }^{\circledR}$ Label-based (L series) RayBiotech]. RayBio ${ }^{\circledR}$ Label-based array contains duplicate spots of 1,000 proteins. The Fig. 1 demonstrates the protein spot and signal intensities of the proteins determined by antibody array. Antibody array identified many proteins that were signal transduction proteins, structural proteins, mitochondrial proteins and proteins related to cellular metabolism. The identified proteins are listed in Table I. Of the 19 identified proteins, the expression of seven proteins were upregulated while the remaining 12 proteins were downregulated in hesperidin-treated HepG2 cells. Among these proteins, the intensities of S100A4, S100A6, calbidin, ROS, Hsp90, FRK, Lyn, Csk and Prdx6 were significant.

Protein-protein interaction. The STRING database was used to analyze the protein-protein interactions. The Fig. 2 indicates 
Table I. Proteins identified by antibody array analysis. HepG2 cells were treated with/without $1 \mathrm{mM}$ hesperidin and the extracted proteins were subjected to RayBio ${ }^{\circledR}$ Label-based antibody array.

\begin{tabular}{|c|c|c|c|c|c|}
\hline Uniprot ID & Symbol & Protein name & P-value & $\begin{array}{l}\mathrm{Up} / \text { down } \\
\text { regulation }\end{array}$ & Biological function \\
\hline P26447 & S100A4 & S100A4 & 0.002 & $\uparrow \uparrow$ & $\begin{array}{l}\text { Calcium binding protein, promotes cell } \\
\text { migration }\end{array}$ \\
\hline P05937 & - & Calbindin & 0.006 & $\uparrow \uparrow$ & Calcium binding protein \\
\hline P08922 & ROS & $\begin{array}{l}\text { Proto-oncogene receptor } \\
\text { tyrosine kinase }\end{array}$ & 0.01 & $\uparrow \uparrow$ & $\begin{array}{l}\text { Cell growth, proliferation regulator, activates } \\
\text { PI3k/Akt pathway, MAPK cascade }\end{array}$ \\
\hline P07900 & Hsp90 & Heat sock protein 90 & 0.03 & $\downarrow \downarrow$ & $\begin{array}{l}\text { Negative inhibitor of apoptosis, activates } \\
\text { MAPK cascade }\end{array}$ \\
\hline P06703 & S100A6 & S100A6 & 0.03 & $\uparrow \uparrow$ & Calcium binding protein \\
\hline P41240 & Csk & $\begin{array}{l}\text { Tyrosine-protein } \\
\text { kinase Csk }\end{array}$ & 0.04 & $\downarrow \downarrow$ & $\begin{array}{l}\text { Cell growth, differentiation, cell migration } \\
\text { regulation }\end{array}$ \\
\hline P42685 & FRK & $\begin{array}{l}\text { Fyn related tyrosine } \\
\text { kinase }\end{array}$ & 0.05 & $\downarrow \downarrow$ & $\begin{array}{l}\text { Suppress growth and function during G1 } \\
\text { and } S \text { phase of cell cycle }\end{array}$ \\
\hline P07948 & Lyn & $\begin{array}{l}\text { Tyrosine-protein } \\
\text { kinase Lyn }\end{array}$ & 0.05 & $\downarrow \downarrow$ & $\begin{array}{l}\text { Regulates activation of MAP kinase } \\
\text { signaling cascade cascade, cell proliferation, } \\
\text { survival, differentiation, migration, } \\
\text { adhesion, degranulation, and cytokine release }\end{array}$ \\
\hline P30041 & $\operatorname{Prdx} 6$ & Peroxiredoxin 6 & 0.05 & $\downarrow \downarrow$ & Cellular protection, cell survival \\
\hline O00409 & FOXN3 & Forkhead box protein N3 & 0.08 & $\downarrow \downarrow$ & $\begin{array}{l}\text { Transcriptional repressor, cell cycle } \\
\text { arrest at } \mathrm{G} 1 \text { and } \mathrm{G} 2 \text { phase }\end{array}$ \\
\hline Q9GK35 & IGF-IIR & $\begin{array}{l}\text { Insulin-like growth } \\
\text { factor type II receptor }\end{array}$ & 0.08 & $\uparrow \uparrow$ & Suppresses tumor growth \\
\hline P21860 & ErbB3 & $\begin{array}{l}\text { Receptor tyrosine-protein } \\
\text { kinase erbB-3 }\end{array}$ & 0.1 & $\uparrow \uparrow$ & Activates MAPK and PI3/Akt pathway \\
\hline Q08881 & Itk & Tyrosine-protein kinase & 0.1 & $\downarrow \downarrow$ & $\begin{array}{l}\text { Itk phosphorylation leads to } \mathrm{Ca}^{2+} \text { release from } \\
\text { ER to the cytoplasm }\end{array}$ \\
\hline Q96CA5 & BRIC7 & Livin & 0.3 & $\uparrow \uparrow$ & Inhibits apoptosis protein family member \\
\hline P27695 & Apex1 & $\begin{array}{l}\text { DNA-(apurinic or } \\
\text { apyrimidinic site) lyase }\end{array}$ & 0.5 & $\downarrow \downarrow$ & Activator of transcriptional repression \\
\hline P0DMV8 & Hsp70 & Heat sock protein 70 & 0.5 & $\downarrow \downarrow$ & Inhibits apoptosis, \\
\hline Q12982 & BNIP2 & $\begin{array}{l}\text { BCL2/adenovirus E1B } \\
19 \mathrm{kDa} \text { protein-interacting } \\
\text { protein } 2\end{array}$ & 0.6 & $\downarrow \downarrow$ & Suppresses cell death \\
\hline Q9NR28 & Smac & $\begin{array}{l}\text { Second mitochondria } \\
\text { derived activator of caspases }\end{array}$ & 0.6 & $\downarrow \downarrow$ & Promotes apoptosis \\
\hline P21741 & - & Midkine & 0.9 & $\downarrow \downarrow$ & $\begin{array}{l}\text { Cell proliferation regulator, activates } \\
\text { MAPK pathway }\end{array}$ \\
\hline
\end{tabular}

Table II. List of predicted functional partners obtained from STRING database.

Protein

Function

SUGT1

STIP1

PTGES3

CDC37

AHSA1
SGT1, suppressor of G2 allele of SKP1 (S. cerevisiae). May play role in ubiquitination and subsequent proteosomal degradation of target proteins

Stress-induced-phosphoprotein 1. Mediates the association of the molecular chaperones Hsc70 and Hsp90 Prostaglandin E synthase 3 (cytosolic). Molecular chaperone that localizes to genomic response elements in a hormone-dependent manner and disrupts receptor-mediated transcriptional activation, by promoting disassembly of transcriptional regulatory complexes

Cell division cycle 37 homolog. Co-chaperone that binds to numerous kinases and promotes their interaction with the Hsp90

AHA1, activator of heat shock $90 \mathrm{kDa}$ protein ATPase homolog 1 
A

A
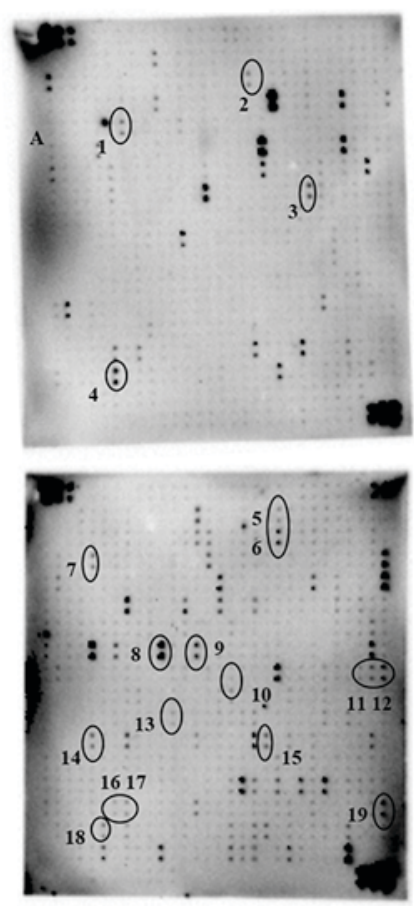

$1 \mathrm{mM}$ hesperidin
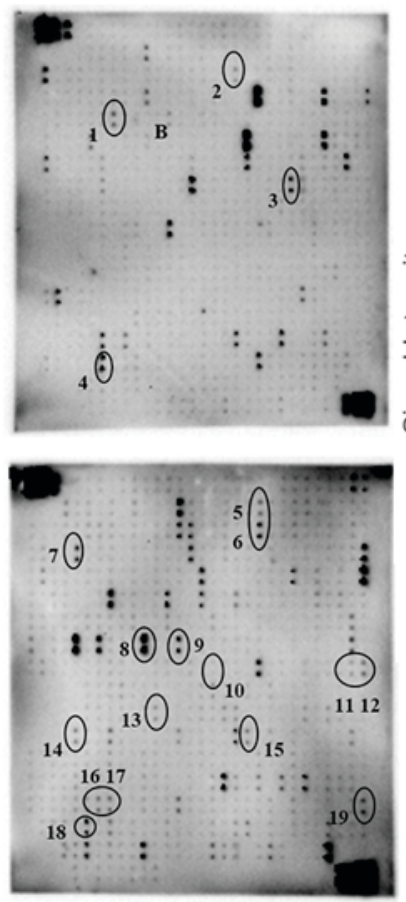

B

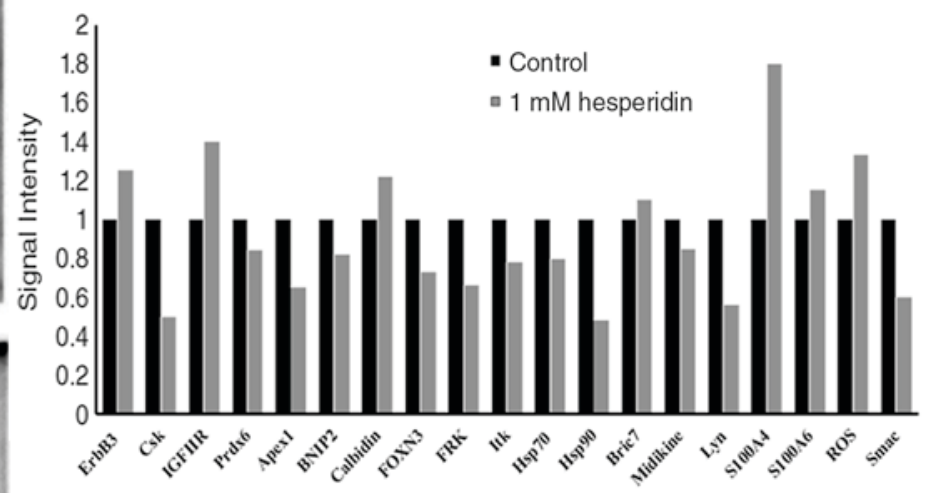

Figure 1. Antibody array analysis of HepG2 cells. (A) Altered protein spots detected during paraptosis. HepG2 cells were treated with or without $1 \mathrm{mM}$ hesperidin and subjected to RayBio ${ }^{\circledR}$ Label-based array. Protein spots: 1, ErbB3; 2, Csk; 3, IGFIIR; 4, Prdx6; 5, calbindin; 6, Apex1; 7, BNIP2; 8, FOXN3; 9, FRK; 10, livin; 11, Itk; 12, Hsp70; 13, Hsp90; 14, Midkine; 15, S100A4; 16, S100A6; 17, ROS; and 18, Smac. (B) Signal intensities of the identified proteins. ERbB3, Receptor tyrosine-protein kinase erbB-3; IGFIIR, insulin-like growth factor type II receptor; Prdx6, peroxiredoxin 6; Apex1, DNA-(apurinic or apyrimidinic site) lyase; BNIP2, BCL2/adenovirus E1B $19 \mathrm{kDa}$ protein-interacting protein 2; FOXN3, forkhead box protein N3; FRK, Fyn related tyrosine kinase; Itk, tyrosine-protein kinase; HSP, heat shock protein; ROS, proto-oncogene receptor tyrosine kinase; Smac, second mitochondria derived activator of caspases.

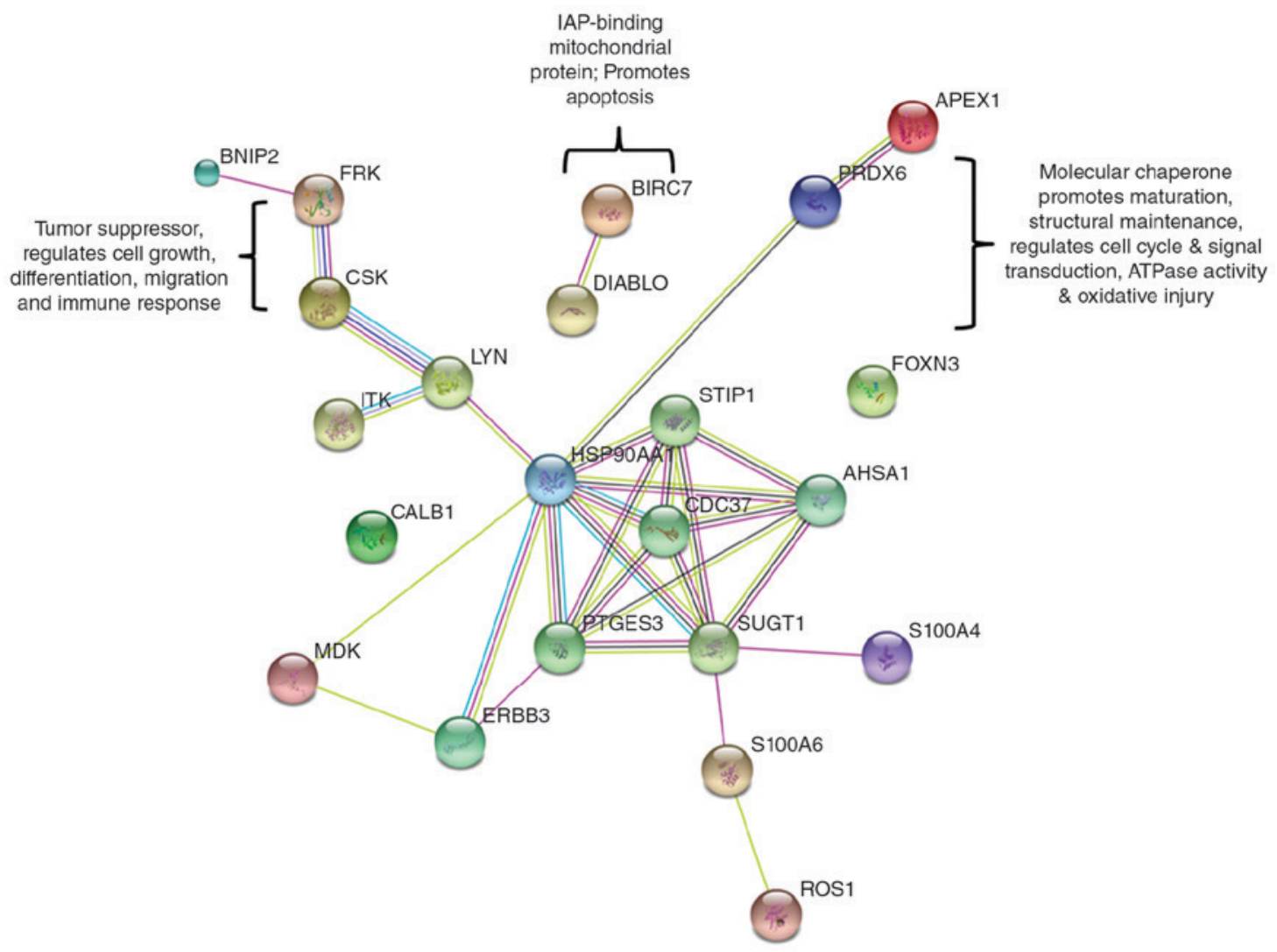

Figure 2. Protein-protein interaction of the identified proteins. STRING database, version 10 (http://string.embl.de) was used to determine the protein-protein interactions of the 18 proteins identified by antibody array analysis. 


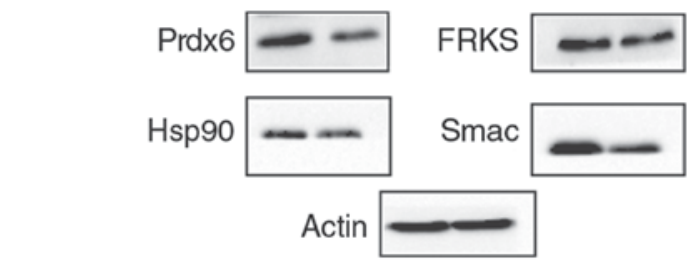

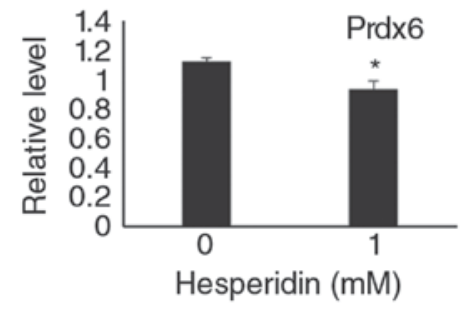

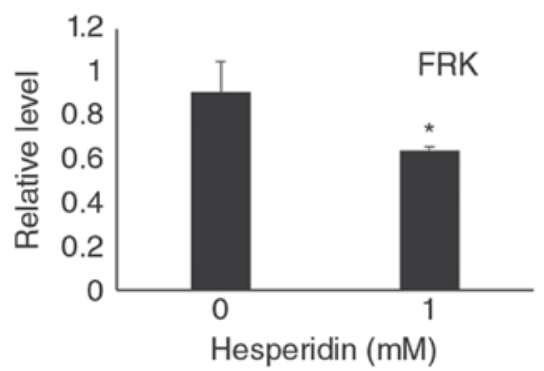

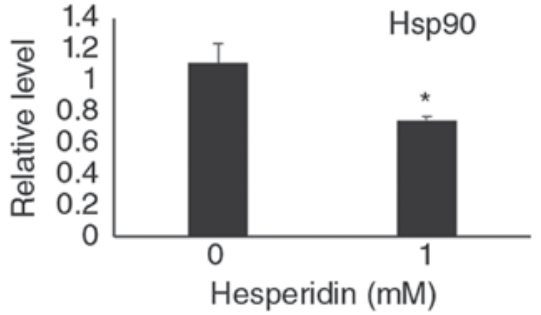

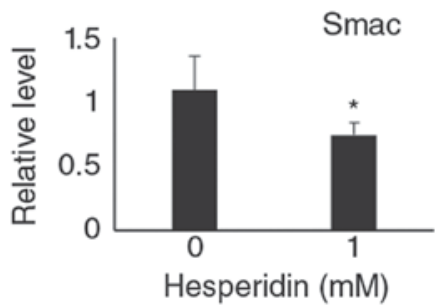

Figure 3. Expression of proteins altered during paraptosis. HepG2 cells were untreated or treated with hesperidin for $24 \mathrm{~h}$ and whole cell lysate prepared from these cells were subjected to western blot analysis. Protein level of Prdx6, Hsp90, FRK and Smac/DIABLO are shown relative to the value for untreated control cells. Data represent the mean \pm standard deviation of three replicates independent experiments. ${ }^{*} \mathrm{P}<0.05$ vs. control. Prdx6, peroxiredoxin 6 ; HSP, heat shock protein; FRK, Fyn related tyrosine kinase.

the protein-protein interaction generated by STRING with a medium confidence of 0.400 . Prdx6 and FRK are directly or indirectly linked to Hsp90 and the combined score between Prdx6 and Hsp90 is 0.454, and that of FRK and Csk is 0.864 . Another node of Diablo and Bric7 with a combined score of 0.993 was also observed. Table II shows the predicted functional partners and their respective functions. As presented in Fig. 2, Hsp90 is the primary functional interacting node in the STRING interaction.

Effect of hesperidin on protein expression. To validate the antibody array analysis results, western blot analysis was conducted using the same cell lysate that were used for antibody array analysis. Immunoblots of Hsp90, Prdx6, FRK and Smac were carried out. Hesperidin significantly reduced the protein expression of Hsp90, Prdx6, FRK and Smac (Fig. 3), which is consistent with the antibody array results.

\section{Discussion}

In the present study, using antibody array techniques identified the proteins involved in hesperidin-induced cell death. Antibody array analysis has the advantaged of measuring multiple proteins in a parallel manner. A total of 19 proteins were identified and STRING analysis of these proteins indicated Hsp90 to be an important node within the entire network. Hsp90 is usually overexpressed in cancer cells and is considered as a potential target in cancer therapeutics. It is a chaperone protein required for the stability of various client proteins and many of these proteins are involved in cell signaling, proliferation and survival $(10,11)$. Thus inhibition of Hsp90 has been considered as a promising way for cancer treatment. In the present study, the protein expression of Hsp90 was significantly reduced in hesperidin treated cells when compared with the untreated control cells. Many Hsp90 inhibitors like geldanamycin, 17-allylamino-17-demethoxygeldanamycin (17-AAG) and 17-dimethylaminoethylamino-17-demethoxygeldanamycin (17-DMAG) are currently being studied as anticancer agents $(12,13)$. There are also studies that Hsp90 inhibition leads to ERK/MAPK activation in human cancer cells $(14,15)$. In a previous study of the authors, it was reported that hesperidin-induced paraptosis occurs in HepG2 cells by activation of the ERK1/2 pathway (5). In addition, it was also observed that Hsp90 is an important node in the protein-protein interaction network. Thus, inhibition of Hsp90 may be an important upstream cascade in hesperidin-induced cell death in HepG2 cells.

Interestingly, protein expression of Smac/DIABLO (second mitochondria-derived activator of caspases/direct inhibitor of apoptosis-binding protein with low $\mathrm{pI}$ ) was significantly reduced in hesperidin-treated HepG2 cells. It is a pro-apoptotic mitochondrial protein and negatively regulates the function of inhibitors of apoptosis proteins (IAPs). It promotes apoptosis by activating caspases (16). It was also observed that livin (BRIC7), a member of the IAP family, was upregulated in hesperidin-treated cells (Table I; Fig. 1). Previously, it was reported that livin promotes degradation of Smac/DIABLO through the proteasome ubiquitination pathway (17). As livin protein expression was upregulated with Smac/DIABLO inhibition by hesperidin treatment, the downstream caspase 
cascade may also be inhibited. As paraptosis is known to be a caspase independent cell death, downregulation of Smac/DIABLO supports the authors' previous results that hesperidin induced cell death in HepG2 cells is caspase independent and non-apoptotic (5).

In our previous study, it was observed that oxidative stress induced by hesperidin leads to paraptotic cell death in HepG2 cells (18). In the present study, it was observed that Prdx6, which is a member of the peroxiredoxins (Prdx) peroxidase family, protein expression was significantly reduced by hesperidin. As an anti-oxidant, Prdx serves a role in controlling intracellular reactive oxygen species expression. Thus, reduced protein expression of Prdx6 by hesperidin may cause the increase in oxidative stress, which further contributes to HepG2 cell death. Previously, it was reported that downregulation of Prdx6 expression has been reported to increase peroxide-induced cell death in liver cancer cells (19) and thiacremonone, an antioxidant which is generated in garlic after high pressure treatment inhibits lung cancer cell growth through inhibition of Prdx6 expression (20). Thus, Prdx6 is an important marker in hesperidin-induced cell death.

Among the proteins identified during antibody array analysis, FRK (Fyn-related tyrosine kinase) expression was also downregulated. FRK belongs to Src non-receptor tyrosine kinase family (21) and inhibition of Src family kinases is considered to be a potential target for cancer therapeutics. Src family kinases are usually overexpressed in a number of cancer cells-lung, colorectal, pancreatic and breast cancer cells (22). FRK is different from other Src family member and is predominantly expressed in epithelial tissues such as liver, kidney and lung (23). Chen et al (24) reported that FRK is overexpressed in liver cancer cells and knockdown of FRK reduces growth in HepG2 cells and cell proliferation in Hep3B cells. Thus, inhibition of FRK is a promising target in liver cancer. In the present study, antibody array analysis also identified many proteins regulating MAPK cascade, $\mathrm{Ca}^{2+}$ binding proteins, cell growth and proliferation regulatory proteins.

To the best of the authors' knowledge, the present study is the first study on using antibody array for protein profiling of paraptosis cell death induced by hesperidin. In the present study, many target proteins were identified and have also demonstrated their interactions with each other. From the protein-protein interaction generated by STRING Hsp90 was identified to be an important node in hesperidin-induced cell death. As a chaperon protein, Hsp90 is required for the stability of various client proteins and many of which are involved in cell signaling, proliferation and survival. As a result, inhibiting Hsp90 may play an important role in hesperidin-induced cell death. As in the authors' previous study, it has been determined that hesperidin induced cell death is paraptosis (5) and these proteins may be involved crucially in inducing cell death. However, further study on these proteins is required to determine their role in paraptosis. Overall, the present study provides a novel insight into the anticancer mechanism of hesperidin.

\section{Acknowledgements}

The present study was supported by a grant from the National Research Foundation of Korea funded by the
Ministry of Science, ICT and Future Planning (grant nos. 2012M3A9B8019303 and 2017R1A2B4003974).

\section{References}

1. Lee CJ, Wilson L, Jordan MA, Nguyen V, Tang J and Smiyun G: Hesperidin suppressed proliferations of both human breast cancer and androgen-dependent prostate cancer cells. Phytother Res 24 (Suppl 1): S15-S19, 2010.

2. Park HJ, Kim MJ, Ha E and Chung JH: Apoptotic effect of hesperidin through caspase 3 activation in human colon cancer cells, SNU-C4. Phytomedicine 15: 147-151, 2008.

3. Lee KH, Yeh MH, Kao ST, Hung CM, Liu CJ, Huang YY and Yeh CC: The inhibitory effect of hesperidin on tumor cell invasiveness occurs via suppression of activator protein 1 and nuclear factor-kappaB in human hepatocellular carcinoma cells. Toxicol Lett 194: 42-49, 2010.

4. Yeh MH, Kao ST, Hung CM, Liu CJ, Lee KH and Yeh CC: Hesperidin inhibited acetaldehyde-induced matrix metalloproteinase-9 gene expression in human hepatocellular carcinoma cells. Toxicol Lett 184: 204-210, 2009.

5. Yumnam S, Park HS, Kim MK, Nagappan A, Hong GE, Lee HJ, Lee WS, Kim EH, Cho JH, Shin SC and Kim GS: Hesperidin induces paraptosis like cell death in hepatoblatoma, HepG2 cells: Involvement of ERK1/2 MAPK [corrected]. PLoS One 9: e101321, 2014.

6. Sperandio S, de Belle I and Bredesen DE: An alternative, nonapoptotic form of programmed cell death. Proc Natl Acad Sci USA 97: 14376-14381, 2000.

7. Siu KW, DeSouza LV, Scorilas A, Romaschin AD, Honey RJ Stewart R, Pace K, Youssef Y, Chow TF and Yousef GM: Differential protein expressions in renal cell carcinoma: New biomarker discovery by mass spectrometry. J Proteome Res 8: 3797-3807, 2009

8. Haab BB, Dunham MJ and Brown PO: Protein microarrays for highly parallel detection and quantitation of specific proteins and antibodies in complex solutions. Genome Biol 2: RESEARCH0004, 2001.

9. Huang R, Jiang W, Yang J, Mao YQ, Zhang Y, Yang W, Yang D, Burkholder B, Huang RF and Huang RP: A biotin label-based antibody array for high-content profiling of protein expression. Cancer Genomics Proteomics 7: 129-141, 2010.

10. Goetz MP, Toft DO, Ames MM and Erlichman C: The Hsp90 chaperone complex as a novel target for cancer therapy. Ann Oncol 14: 1169-1176, 2003.

11. Richter K and Buchner J: Hsp90: Chaperoning signal transduction. J Cell Physiol 188: 281-290, 2001.

12. Chen TL, Gupta N, Lehman A, Ruppert AS, Yu L, Oakes CC, Claus R, Plass C, Maddocks KJ, Andritsos L, et al: Hsp90 inhibition increases SOCS3 transcript and regulates migration and cell death in chronic lymphocytic leukemia. Oncotarget 7: 28684-28696, 2016.

13. Modi S, Stopeck A, Linden H, Solit D, Chandarlapaty S, Rosen N, D'Andrea G, Dickler M, Moynahan ME, Sugarman S, et al: HSP90 inhibition is effective in breast cancer: A phase II trial of tanespimycin (17-AAG) plus trastuzumab in patients with HER2-positive metastatic breast cancer progressing on trastuzumab. Clin Cancer Res 17: 5132-5139, 2011.

14. Donzé O, Abbas-Terki T and Picard D: The Hsp90 chaperone complex is both a facilitator and a repressor of the dsRNA-dependent kinase PKR. EMBO J 20: 3771-3780, 2001.

15. Koga F, Xu W, Karpova TS, McNally JG, Baron R and Neckers L: Hsp90 inhibition transiently activates src kinase and promotes src-dependent akt and erk activation. Proc Natl Acad Sci USA 103: 11318-13322, 2006.

16. Martinez-Ruiz G, Maldonado V, Ceballos-Cancino G, Grajeda JP and Melendez-Zajgla J: Role of smac/DIABLO in cancer progression. J Exp Clin Cancer Res 27: 48, 2008.

17. Ma L, Huang Y, Song Z, Feng S, Tian X, Du W, Qiu X, Heese $\mathrm{K}$ and $\mathrm{Wu} \mathrm{M}$ : Livin promotes smac/DIABLO degradation by ubiquitin-proteasome pathway. Cell Death Differ 13: 2079-2088, 2006.

18. Yumnam S, Hong GE, Raha S, Saralamma VV, Lee HJ, Lee WS, Kim EH and Kim GS: Mitochondrial dysfunction and $\mathrm{Ca}(2+)$ overload contributes to hesperidin induced paraptosis in hepatoblastoma cells, HepG2. J Cell Physiol 231: 1261-1268, 2016.

19. Walsh B, Pearl A, Suchy S, Tartaglio J, Visco K and Phelan SA: Overexpression of Prdx6 and resistance to peroxide-induced death in Hepa1-6 cells: Prdx suppression increases apoptosis. Redox Rep 14: 275-284, 2009. 
20. Jo M, Yun HM, Park KR, Park MH, Lee DH, Cho SH, Yoo HS, Lee YM, Jeong HS, Kim Y, et al: Anti-cancer effect of thiacremonone through down regulation of peroxiredoxin 6. PLoS One 9: e91508, 2014.

21. Lee J, Wang Z, Luoh SM, Wood WI and Scadden DT: Cloning of FRK, a novel human intracellular SRC-like tyrosine kinase-encoding gene. Gene 138: 247-251, 1994.

22. Wheeler DL, Iida M and Dunn EF: The role of src in solid tumors. Oncologist 14: 667-678, 2009.
23. Irby RB and Yeatman TJ: Role of src expression and activation in human cancer. Oncogene 19: 5636-5642, 2000.

24. Chen JS, Hung WS, Chan HH, Tsai SJ and Sun HS: In silico identification of oncogenic potential of fyn-related kinase in hepatocellular carcinoma. Bioinformatics 29: 420-427, 2013. 